\title{
Universiteit
}

Leiden

The Netherlands

\section{A theoretical framework and questionnaire for wonder-full education}

Conijn, J.M.; Rietdijk, W.; Broekhof, E.; Andre, L; Schinkel, A.

\section{Citation}

Conijn, J. M., Rietdijk, W., Broekhof, E., Andre, L., \& Schinkel, A. (2021). A theoretical framework and questionnaire for wonder-full education. J Curriculum Stud.

doi:10.1080/00220272.2021.1942992

Version: $\quad$ Publisher's Version

License: $\quad$ Licensed under Article 25fa Copyright Act/Law (Amendment Taverne)

Downloaded from: https://hdl.handle.net/1887/3263710

Note: To cite this publication please use the final published version (if applicable). 


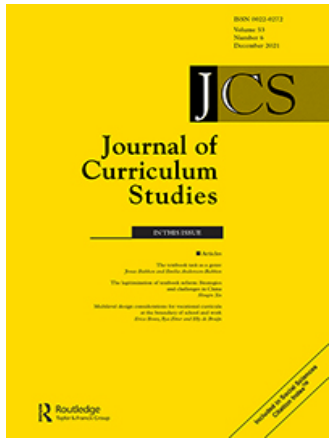

Journal of Curriculum Studies

ISSN: (Print) (Online) Journal homepage: https://www.tandfonline.com/loi/tcus20

\section{A theoretical framework and questionnaire for wonder-full education}

Judith M. Conijn, Willeke Rietdijk, Evelien Broekhof, Lucija Andre \& Anders Schinkel

To cite this article: Judith M. Conijn, Willeke Rietdijk, Evelien Broekhof, Lucija Andre \& Anders Schinkel (2021): A theoretical framework and questionnaire for wonder-full education, Journal of Curriculum Studies, DOI: 10.1080/00220272.2021.1942992

To link to this article: https://doi.org/10.1080/00220272.2021.1942992

册 Published online: 20 Aug 2021.

Submit your article to this journal $₫$

!ll Article views: 235

Q View related articles ¿

View Crossmark data 


\title{
A theoretical framework and questionnaire for wonder-full education
}

\author{
Judith M. Conijn (D) ${ }^{a}$, Willeke Rietdijk (D) ${ }^{a}$, Evelien Broekhof $\mathbb{D}^{a}$, Lucija Andre (D) ${ }^{a, b}$ \\ and Anders Schinkel iD $^{a}$ \\ aDepartment of Educational and Family Studies, VU University Amsterdam, Amsterdam, The Netherlands; \\ ${ }^{\text {b}}$ Research Institute of Child Development and Education, University of Amsterdam, Amsterdam, The Netherlands
}

\begin{abstract}
Many recent studies emphasize the fundamental importance of stimulating wonder in education, for example, to increase children's intrinsic motivation to learn and their emotional engagement with the lesson contents. Our study advances the research regarding wonder in education in three different ways. First, we present a theoretical framework to identify eight teaching strategies and three school policy dimensions relevant for teachers and schools to stimulate wonder in children. Second, based on this framework, we developed the multidimensional Wonder-full Education questionnaire (WEQ). The WEQ is completed by teachers and principals to quantitatively assess the degree to which primary schools and their teachers provide a wonder-stimulating environment. Third, using comprehensive psychometric analyses of the data of $N=220$ teachers and $N=91$ principals from 182 Dutch schools, we investigated the dimensionality, reliability and validity of the WEQ. The dimensionality analyses identified two primary dimensions of teaching strategies and confirmed the three-dimensional structure of a school policy for stimulating wonder. Overall, the results suggest that the WEQ has satisfactory psychometric properties. We conclude that the new framework and questionnaire allow research regarding wonder in education to be extended from mainly theoretical work to empirical research that can also advance educational practice.
\end{abstract}

\section{KEYWORDS}

wonder; wonder-full education questionnaire; teaching strategies; school policy; validation

\section{Introduction}

There is an increasing body of theoretical studies that elaborates on the importance of stimulating and fostering wonder in education (e.g. Egan et al., 2014; Geller et al., 2020; L'Ecuyer, 2014; Di Paolantonio, 2019; Schinkel, 2017, 2019). Other studies discuss the specific value of wonder in science education (e.g. Gilbert \& Byers, 2017; Hadzigeorgiou \& Schulz, 2019; Lindholm, 2018; Stolberg, 2008), environmental education (e.g. Hadzigeorgiou \& Judson, 2017; Jørgensen, 2016; Washington, 2018), and medical education (Geller et al., 2018). However, misconceptions about the concept of wonder, such as wonder being associated mainly with passiveness or with fiction such as magic and miracles, may have contributed to a lack of attention for wonder in educational practice (Hadzigeorgiou, 2014).

Scholars have conceptualized wonder in different ways, but most agree on several defining common aspects of wonder (Hadzigeorgiou, 2014; Schinkel, 2019): to experience wonder is to perceive something as strange or beyond current comprehension; the experience includes affective 
components (e.g. feelings of surprise and a sense of the importance of what one is contemplating) but also the cognitive awareness that one's knowledge is incomplete; finally, wonder is similar to, but not the same, as curiosity (Hadzigeorgiou, 2014; Opdal, 2001; Schinkel, 2020). One of the main differences is that in curiosity the drive for receiving specific information is central to the experience (Kashdan \& Silvia, 2009), while wonder refers to a receptive state of mind that foregrounds the object of wonder. Curiosity therefore dissolves by receiving the required information, while wonder does not necessarily end by an increased understanding of a phenomenon (e.g. how a rainbow originates) but may persist also when fully understanding the 'object' of wonder. A related difference is that curiosity is always concerned with something new, but wonder can also concern something familiar that is seen in a new light (Schinkel, 2017).

Theoretical studies discussed a variety of effects to substantiate the importance of wonder in education. These studies suggest that experiencing wonder increases students' intrinsic motivation to learn and to investigate, as well as their general interest in the world (e.g. Hadzigeorgiou, 2014; L'Ecuyer, 2014; Di Paolantonio, 2019; Schinkel, 2017; Wolbert \& Schinkel, 2020). Also, studies propose that wonder makes students more open to (novel) experiences and encourages them to suspend judgment and set aside 'existing — potentially limiting - ways of thinking, seeing, and categorizing' (Schinkel, 2017, p. 538; see also; Hadzigeorgiou, 2014; Opdal, 2001). Moreover, stimulating wonder in education is believed to increase students' emotional engagement with a lesson content (Hadzigeorgiou, 2014). This emotional engagement should in turn increase the likelihood that students continue to think about the information, resulting in better retrieval of information, better conceptual understanding, and enhanced critical thinking (Hadzigeorgiou, 2014). Next to the theoretical studies, several empirical studies have also supported the link between stimulating wonder on the one hand and emotional engagement and better retrieval of information on the other (Gilbert \& Byers, 2017; Hadzigeorgiou et al., 2012; Hadzigeorgiou, 2012), justifying the need for more research into wonder in education.

The term wonder-full education was first introduced by Egan et al. (2014) and has thereafter also been used by Wolbert and Schinkel (2020) and Schinkel (2021a). These studies indicate what distinguishes wonder-full education from education in which wonder plays no important role, propose 'techniques' to generate and keep alive wonder, and describe which educational conditions promote or hinder wonder in education. However, to date, an overview of educational strategies and school policy aspects for wonder-full education is missing. Moreover, due to the lack of an instrument to assess the different aspects of wonder-full education, the literature offers little possibility to conduct empirical research into education for wonder and also to assess the effects of wonder-full education. Thus, the present study addresses two issues. In the first and theoretical part of our study, we summarize existing theoretical and empirical work into a theoretical framework of wonder-full education. In the second and empirical part of our study, we describe the development and the validation of a multidimensional questionnaire that was based on our theoretical framework: the Wonder-full Education Questionnaire (WEQ). The WEQ quantitatively assesses the degree to which primary schools and their teachers provide a wonder-stimulating environment. In the quantitative validation study, we investigate the validity, dimensionality, and reliability of the newly developed multidimensional measure of wonder-full education.

\section{Theoretical framework for wonder-full education}

To propose a comprehensive framework based on the literature, we first made a distinction between three broad dimensions within primary education that were expected to directly or indirectly shape wonder-full education and thus affect children's possibilities to experience wonder at school. The first dimension refers to the teachers' teaching strategies and was regarded as the most important dimension based on the reviewed literature. The interaction between teachers and children, and the activities that the teachers use in this regard, are expected to offer the primary and most direct contribution to the likelihood that children experience wonder (L'Ecuyer, 2014; Wolbert \& Schinkel, 
2020). As Trotman (2014, p. 34) writes: '[T] he capacity to generate and sustain wonder will always be in the hands of the skilful educator-one who is able to nurture and enrich such moments beyond the initial "wow!" of novelty'.

Considering that teachers' opportunities to promote wonder are affected by the environment they work in, we identified two different dimensions of school policy as additional determining variables for wonder-full education. A first important determining variable of a wonder-supporting school policy is the school mission as described in the (written) mission and vision statement of the school (Fleming, 2014). However, the extent to which this mission is actually implemented in the daily school practice may be even more important in supporting teachers to promote wonder (Wolbert \& Schinkel, 2020). Therefore, we highlight school practice as the second determining variable of a wonder-supporting school policy. We elaborate on each of these three dimensions in the following two sections.

\section{Teaching strategies and wonder}

Based on the reviewed literature, we identified eight teaching strategies that are relevant for stimulating wonder in primary school children. The eight teaching strategies refer to things that teachers do, broadly conceived, including ways in which they relate to children as well as more concrete pedagogical actions. The term 'strategies' was chosen for pragmatic reasons to cover all of these ways in which teachers may foster children's wonder. The first two strategies concern ways of being as much as ways of acting; still, when it comes to promoting wonder, what teachers doexpressing their sensitivity to children's wonder, for instance-is crucially important. The last six strategies more explicitly concern teachers' use of specific activities in education. Each of these teacher strategies and the activities that they involve are to some extent related and can thus be combined and built upon one another in the educational process. Some of the strategies rely on recognized and widely applied teaching methods and theories in education and psychology. For these more familiar strategies, the specific added value of our framework is that we have identified these approaches, or particular aspects thereof, as effective for evoking and supporting children's experience of wonder.

First, teachers can foster wonder by being sensitive to children's personal wonder experience (e.g. Bianchi, 2014; L'Ecuyer, 2014). Such sensitivity relates to Van Manen's (2016) concept of pedagogical tact and implies that teachers acknowledge children's wonder experience and they further guide it. For example, by taking sufficient time to show an active interest in children's discoveries or unexpected viewpoints, and by well-placed remarks, drawing children's attention to remarkable features that evoked their wonder (Hadzigeorgiou, 2020). The underlying idea here is that children can best develop and sustain their ability to wonder if at least one adult empathizes with their personal wonder experience (Carson, 1998).

Second, teachers can stimulate wonder by displaying and sharing their personal wonder experiences and fascinations (e.g. Di Paolantonio, 2019; Piersol, 2014; Schinkel, 2019; Wolbert \& Schinkel, 2020). In this way, the teacher is seen as a role model. To wonder-for example, about the lesson topic-opens up possibilities to inspire the children. The relevance of this strategy is also supported by social learning theory, and moral character education, which regard modelling as fundamental for the learning process (Bandura \& Walters, 1977). To see this relevance, it is important that wonder can be dispositional, so can form a stable 'tendency' that is part of a person's character (Schinkel, 2018, 2021a; Vasalou, 2015). Since wonder as a valuable disposition is comparable to virtues (which are also valuable dispositions), it is plausible that, as in the promotion of virtues, modelling the desired quality can play an important role.

Third, teachers can allow children to explore and experiment by creating conditions for exploration, theory-building, hypothesis testing, and reflection (Bianchi, 2014; Hadzigeorgiou, 2012; Trotman, 2014). By stimulating children's exploration in the educational setting, this strategy is closely linked with inquiry-based science education, or more broadly with science, technology, 
engineering, and mathematics (STEM) education, as well as with play and exploration (e.g. Pedaste et al., 2015; Vygotsky, 1978). Yet, within our framework, the goal of exploration and experimentation activities is to purposefully and consciously evoke wonder in children. Specifically, the time and space offered to children for questioning and reflection is fundamental to stimulating wonder within this strategy (Bianchi, 2014; Hadzigeorgiou, 2012). To illustrate, in Hadzigeorgiou's (2012) study, wonder was stimulated during a lesson on Newton's third law by having students make predictions about the magnitude of the force exerted on two colliding vehicles. Using the topic theory, the teacher then challenged students' hypotheses and students could adjust them. Exploration and experimentation can include the more standardized scientific experiments but can also be facilitated throughout the curriculum by providing children with sufficient time to first investigate new concepts or situations themselves.

Fourth, teachers can stimulate meaning-making with the lesson content. This includes guiding children to construct their own meanings and understandings about different concepts and phenomena (Bianchi, 2014; Hadzigeorgiou, 2012). Meaning-making is stimulated for example, by allowing children to work on topics that they find important or by letting them form connections between the studied topic and their own life (Trotman, 2014). The importance of meaning-making has long been stressed by (socio-)constructivist approaches (Hein, 1991; Vygotsky, 1978), which underlie inquiry-based learning, but also other approaches that may stimulate wonder, such as problembased learning.

Fifth, teachers can also stimulate the imagination of their pupils. For example, by telling fictional stories that are related to the lesson content and letting children create stories or artwork (e.g. Egan, 2014; Hadzigeorgiou \& Schulz, 2019; Piersol, 2014). This strategy of stimulating the imagination has the potential to increase children's wonder experience through evoking surprise and fascination with subject matter (Piersol, 2014). An example of such a practice is the imaginative approach to learning developed by Egan-a strategy in which students' imagination is engaged by organizing the lesson content into a narrative structure (Egan, 1992, p. 81). Hadzigeorgiou et al. (2012) report that students' wonder about the production of alternating current was stimulated by telling the story behind the inventor Nikola Tesla, which was characterized by persistence and controversy. The story provided insight into the human context from which physical ideas arise and thus increased the 'romantic understanding' of the curriculum (see Egan, 1990). Vygotsky-inspired pedagogical approaches often also highlight the importance of stimulating children's imagination (e.g. Hakkarainen, 2004; Lindqvist, 1996; Marjanovic-Shane et al., 2011). Lindqvist (1996) elaborated on the use of various imaginative activities and creative arts (drama, music, etc.) as powerful learning tools and Hakkarainen (2004) described the use of narrative stories among children and adults.

Sixth, wonder in children can also be stimulated by defamiliarizing the familiar, which means that teachers guide children to find the strange, mysterious, and wonderful in the everyday (Egan, 2014; Hadzigeorgiou, 2014; Piersol, 2014). Teachers can do this by, for example, elaborating on the extraordinariness of common phenomena (e.g. a magnet holding a paper clip up despite earth's gravity pulling it down) or by asking probing questions that provide children with new insights concerning everyday objects (Hadzigeorgiou, 2014). Egan (2014) proposed that learning to see anything as wonderful or strange is a specific technique that should be taught to children in a wonder-full curriculum.

Seventh, teachers can encourage contemplation. With the use of the term contemplation, we refer in particular to an attentive awareness, sensory rather than cognitive, to what presents itself in the moment, in the outer as well as the inner world (Barbezat \& Bush, 2014). Paying close attention to what is happening in the world around and/or inside oneself can result in richer experiences and also in becoming aware of aspects of experiences that one had previously been unaware of or overlooked, and therefore this kind of attention provides more opportunity for wonder (Carson, 1998; Hadzigeorgiou, 2020; Jørgensen, 2016; Trotman, 2014). Contemplation requires an atmosphere of calm as well as going slow, as the quality of attention and sensory experience are central. Teachers can include contemplation in their lessons in different ways. For example, they might emphasize 
paying attention to the sensory experience of the world around us (e.g., as part of science education), or they might create space for pupils to pay attention to what is happening in their inner world (e.g., as part of social-emotional learning). Employing contemplation in this way is one aspect of contemplative pedagogy, which has gained increasing popularity in recent years (Morgan, 2015). For a comprehensive overview and understanding, see also Seidel (2006) and Gunnlaugson et al. (2014).

Eight, teachers can create an enriched environment by offering activities, tools, and objects that can inspire children and provide opportunities for exploration and discovery. This includes a wide range of activities outside but also within the school, such as guiding children to discover nature (Jørgensen, 2016; Piersol, 2014; Trotman, 2014; Washington, 2018), artworks, or culture (D'Olimpio, 2020; Yun, 2018), or the use of technology to induce the students' awe and puzzlement (Bianchi, 2014; Fleming, 2014; Trotman, 2014). For example, engagement with art may promote wonder by inviting an open, receptive mode of experiencing, and stimulating children to attend to things more closely and consciously (D'Olimpio, 2020; Glăveanu, 2017; Washington, 2018).

Finally, we may note that we consider the eight teaching strategies as generalizable across the school curriculum for the stimulation of wonder rather than domain specific. Egan's imaginative approach, for example, can be used equally well to tell the story of a Styrofoam cup (Egan, 1992, p. 81), a letter from the First World War, a new virus, a mathematical insight, or a popular song. Also, even though the exploration and experimentation strategy is often associated with STEM subjects, it is also applied in the humanities and social sciences (cf. Blessinger \& Carfora, 2015).

\section{School policy and wonder}

From the theoretical literature, we derived three aspects of a wonder-supporting school policy. Each of these aspects reflects in some way or another that if a school wants to promote wonder in children, there should be time for 'aimless' exploration (Schinkel, 2020; Trotman, 2014). Furthermore, these school policy aspects also have in common that they create the conditions for teachers to engage in the previously described teaching strategies for promoting wonder.

First, the school stimulates children to (cognitively, emotionally, or physically) be actively engaged (e.g. Fleming, 2014; Schinkel, 2020; Wolbert \& Schinkel, 2020): to be curious and inquisitive, to engage all their senses, to make a personal connection with the subject matter and to discover their own specific interests. We refer to this school policy aspect as child-focused education.

Second, the school stimulates-or at least allows - teachers to take time during lessons for children's interests, as well as for their own, which may lead children to discover new interests (Fleming, 2014; Di Paolantonio, 2019; Trotman, 2014; Wolbert \& Schinkel, 2020). Under such circumstances, teachers can act optimally as role models and be sensitive to children's wonder. This requires that time or student performance (e.g. on standardized tests) is not a source of inordinate pressure and that teachers are allowed to deviate from lesson plans if something fascinating emerges. We refer to this school policy aspect as the contrary of test- and method centred education.

Third, the school aims to offer an enriched environment for children outside the school or using facilities within the school. An enriched environment can for example, be offered through a 'green' school yard or trips into nature, by culture (excursions) or technology facilities at school (Fleming, 2014; Jørgensen, 2016; Piersol, 2014; Trotman, 2014). This dimension is heterogenous as an enriched environment can take different forms (e.g. some schools may focus more or culture and other more on nature), but the different types of 'enriched environments' have in common that they go beyond the standard teaching materials and offer a rich learning experience both inside or outside the classroom in which all the faculties and senses are engaged. We refer to this school policy aspect as enriched education. 


\section{Empirical study}

In the next sections, we present the wonder-full education questionnaire as an operationalization of the wonder-full education framework and provide the results of a study investigating its psychometric properties. In the Discussion section, we discuss the implications of the psychometric results for both the use of the questionnaire as well as the theoretical framework. Finally, we propose various ideas for future research that can be realized using the wonder-full education framework and corresponding questionnaire.

\section{Materials and methods}

\section{Participants and procedure}

The data collection for the psychometric validation study was part of a larger Dutch study of our research team on the effects of stimulating wonder in primary education (Schinkel, 2021b). This larger study included different informants (children, parents, teachers). For the current study we only used the teacher data (grades 6 to 8 ) and principal data that were collected via an online questionnaire constructed in Survalyzer (https://www.survalyzer.com/). The online questionnaire included the WEQ for teachers and school principals (see the 'Measurement instruments' section) and next to it several background variables (e.g. work experience, specific tasks at school, religious affiliation of the school). The total time to complete the questionnaire was about 20 minutes for teachers and 10 minutes for principals.

We used three ways for recruiting participants. First, we invited schools by email to participate in the larger study (i.e. including also parents and children). Second, we recruited schools to participate in a less comprehensive version of the study, involving only the online questionnaires for teachers and principals. Third, we recruited individual respondents by distributing the link to the online questionnaire via primary school related emailing lists and posting the link on relevant Facebook group pages. Participating schools in the larger study received a voucher of 100 Euros to spend on teaching materials as an appreciation for their participation. In the two less comprehensive versions of the study, teachers received an online voucher of 10 euros while principals were not compensated because they completed a shorter questionnaire than teachers.

The resulting sample consisted of $N=220$ teachers and $N=91$ principals from 182 different schools in the Netherlands. Among these schools, in 47 schools a principal as well as at least one teacher participated. The teachers ( $83 \%$ female) had a mean age of $40(S D=11.0)$. The number of teachers from the same school ranged from 1 to 6 teachers per school, but for most of the schools (70\%) only one teacher participated. Teachers worked in grade $6(n=68)$, grade $7(n=129)$, and grade $8(n=144)$. Of the 91 participating principals (63\% female, mean age $=49, S D=9.6)$, two worked at the same school and five principals also worked as a class teacher in grade 6, 7 or 8 . Although participating teachers and principals did not come from the same school, the distribution of school type was similar for principals and teachers: around $61 \%$ of the respondents worked in a school with a Protestant-Christian, Catholic or a more specific religious background and around $21 \%$ worked in a school with a specific educational philosophy such as the Montessori or Dalton method.

\section{Measurement instruments}

Based on our theoretical framework, we developed the Wonder-full Education Questionnaire (WEQ) as a two-part instrument: 1) the main questionnaire called the Teacher WEQ, and 2) the supplementary questionnaire called the School Policy WEQ. The Teacher WEQ is for administration to primary school teachers and aims to measure: (a) the degree to which teachers use strategies that stimulate wonder in children during their lessons, and (b) the degree to which teachers perceive their working environment as favourable for using these strategies in their classes. The School Policy WEQ is for 
Table 1. An Overview of the (Sub)Scales of the Wonder-full Education Questionnaire

\begin{tabular}{|c|c|c|c|c|}
\hline Questionnaire & Scale & Subscale & $\begin{array}{l}\text { Teacher } \\
\text { report }\end{array}$ & $\begin{array}{c}\text { Principal } \\
\text { Report }\end{array}$ \\
\hline Teacher WEQ & Teaching Strategies & $\begin{array}{l}\text { Teacher as a role model (TRM) } \\
\text { Teacher sensitivity (TS) } \\
\text { Exploration and experimentation (EE) } \\
\text { Defamiliarizing the familiar (DF) } \\
\text { Meaning making (MM) } \\
\text { Stimulating the imagination (SI) } \\
\text { Creating enriched environment (CEE) } \\
\text { Encouraging contemplation (CO) }\end{array}$ & Yes & No \\
\hline & Teaching Conditions & $\mathrm{N} / \mathrm{A}$ & Yes & No \\
\hline School Policy WEQ & School Mission/ School Practice ${ }^{1}$ & $\begin{array}{l}\text { Child focused education (CE) } \\
\text { Test and method centered education (TME) } \\
\text { Enriched education (EnE) }\end{array}$ & Yes & Yes \\
\hline
\end{tabular}

Note. 'Items in the School Mission dimension are administered to school principals and items in the School Practice dimension are administered to teacher

administration to both primary school principals and teachers and aims to measure the extent to which a primary school's mission and its practical implementation facilitate the stimulation of wonder in children. The Teacher WEQ is designed for teachers of 9- to 12-year-old children (corresponding to grades 6 to 8 in the Dutch school system), whereas the School Policy WEQ is not designed for teachers or principals of a specific range of grades. See Table 1 for an overview of the scales and subscales of the WEQ for teachers and school principals.

The Teacher WEQ consists of three to five statements for each of the eight teaching strategies, totalling 33 statements (see Table 2). Two questions are asked for each statement: 1) 'Is the statement applicable?' and 2) 'To what extent do your working conditions provide sufficient opportunity to do this?'. Both questions are rated on a 4-point Likert scale ranging from 1 (not at all) to 4 (completely). The first question contributes to the measurement of the corresponding subdimension of the Teaching Strategies scale. The second question was added for two reasons: to reduce the likelihood of socially desirable responding to the first question and to gain information on the individual teaching conditions. We expected the individual teaching conditions to be partly related to the school's policy, but partly also to vary across teachers due to differences in work experience or the experienced pressure to educate 'efficiently and effectively', or the specific demands of a teacher's class and pupils.

The School Policy WEQ includes three subscales to rate various aspects of the school mission (using a questionnaire for principals) and the daily practice of the school (using a questionnaire for teachers). The questionnaires for principals and teachers include the same three subscales (i.e. childfocused education, test and method centred education, and enriched education) and the same 17 items in total (see Table 3). However, principals are instructed to respond to the items based on aims, norms and values such as those described in the school mission, while teachers are instructed to respond to the items based on the daily practice of the school. Items are rated on a 3-point Likert scale with options 1 (does not really apply), 2 (applies somewhat), and 3 (totally applies). Items are (re-) coded such that higher scores on each of the subscales are indicative of a more 'wonder-full' school policy.

The final version of the WEQ was based on the results of a pre-test study using a preliminary WEQ, in which a sample of 19 teachers, three principals, and two external academic experts in stimulating wonder in education participated. The aim of this pre-test study was to validate the items by establishing face validity and content validity. The participants were instructed to fill in the questionnaire and to indicate whether items and instructions were clear for them and whether relevant 


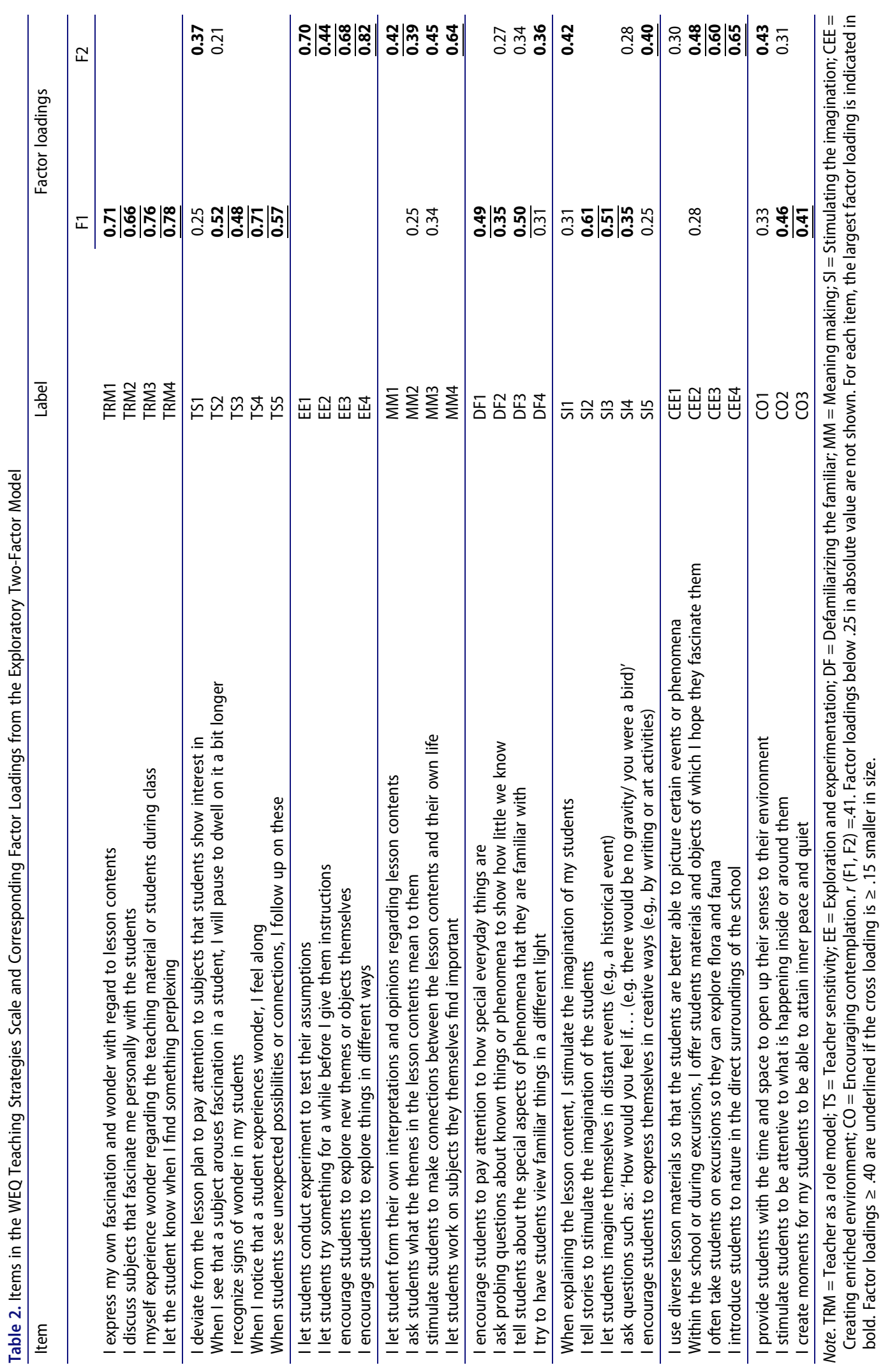




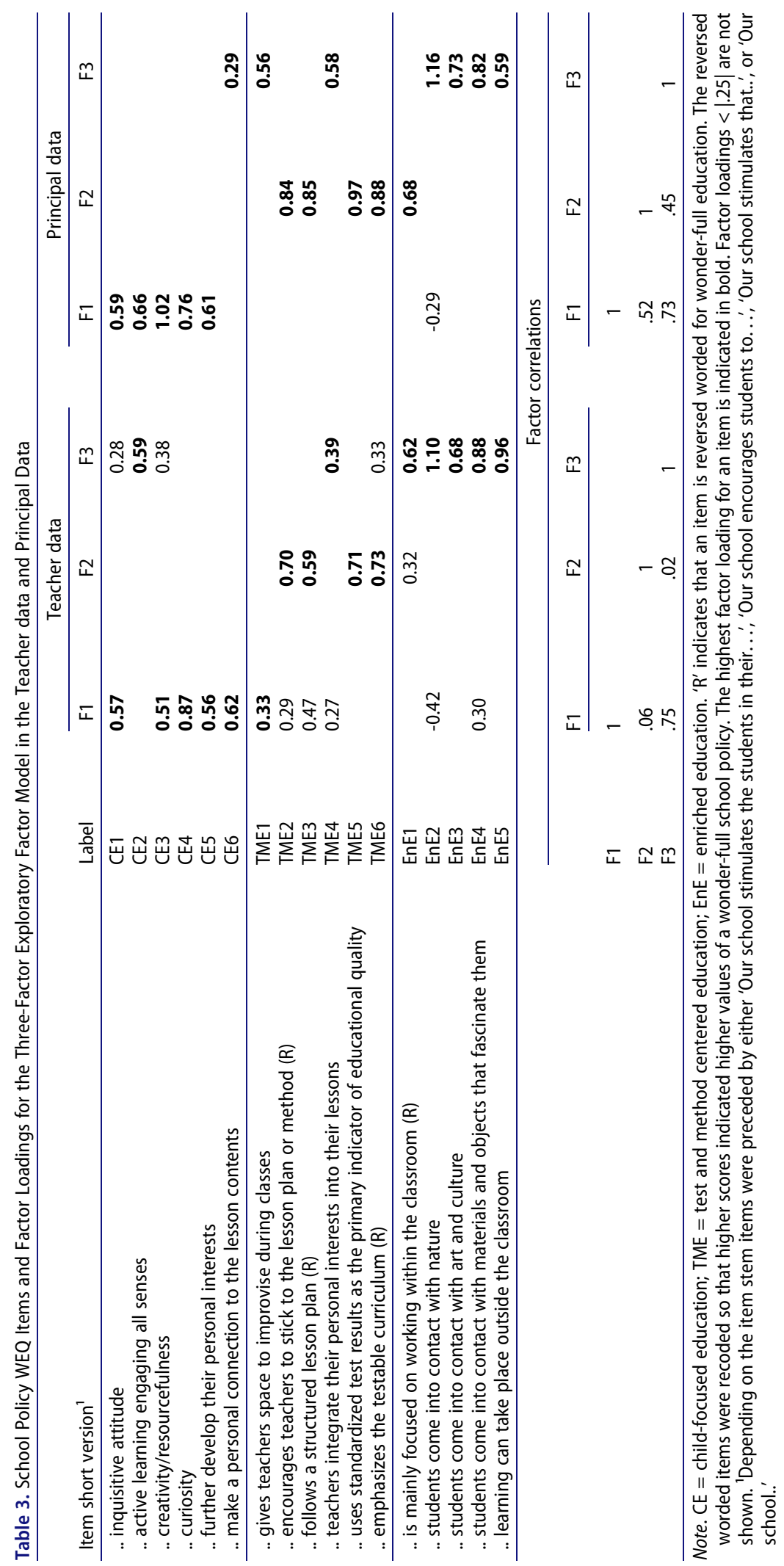


topics were missing from the questionnaire. Five of the participants provided their feedback in an interview; the remaining participants provided online comments. Based on the results, the items were adapted and nine new items were added to the questionnaire. The relevance of the eight teaching strategies for stimulating wonder according to teachers and principals was supported by other recent studies (Broekhof et al., 2021; Conijn et al., 2020).

\section{Statistical analyses}

In item analyses, we inspected item frequency distributions and corrected item-total correlations (with correlations < .20 regarded as problematic). Scale scores were computed for each of the (sub) scales listed in Table 1. Because missing data were present for $<2 \%$ of the respondents and did not include more than half of the items in a subscale, subscale scores were computed based on mean score imputation. We used Cronbach's alpha as an estimate of the reliability of (sub)scale scores.

\section{Dimensionality}

Dimensionality analyses were conducted to assess whether the subdimensions in Table 1 could be confirmed statistically or whether an alternative and/or a simpler structure was more appropriate. These analyses were conducted separately for three main dimensions of wonder-full education as well as the added Teaching Condition dimension (see Table 1). We started the dimensionality assessment with an analysis of the eigenvalues based on the polychoric correlation matrix. Specifically, we assessed the ratio between the first and second eigenvalue to assess the strength of the primary dimension (a ratio $>4$ was taken as support for unidimensionality) and conducted parallel analysis in the 'psych' R package (Revelle, 2021) to estimate the number of factors in the data. Next, based on the estimated number of factors in the parallel analysis, we conducted exploratory factor analysis (EFA) with oblique Geomin factor rotation (i.e. allowing factors to be correlated) to identify one or more plausible factor structures for the item data. Finally, we estimated confirmatory factor analysis (CFA) models corresponding to the competing models identified in the EFA. The RMSEA, CFI and TLI were used to assess CFA model fit. RMSEA values $\leq .08$ and $\leq .05$ indicate an acceptable and good fit, respectively (Browne \& Cudeck, 1993; MacCallum et al., 1996). For both the CFI and TLI, values $\geq .90$ and $\geq .95$ indicate an acceptable and good model fit, respectively (Hu \& Bentler, 1999). For the factor analyses, we used the programme Mplus (Muthén \& Muthén, 19982017) and a robust weighted least squares estimator to account for the ordinal nature of the response scale.

\section{Validity coefficients}

We computed two types of validity coefficients. First, we computed the within-school intra-class correlations (ICCS) for each of the teacher-reported scores (see Table 1). The ICC indicates the proportion of total variance in scores that is due to variation between schools. Higher values indicate that a specific score is to a larger extent school-dependent instead of teacher-dependent. We expected the highest ICCs for the (sub)scales that theoretically related most strongly to the school environment: each of the School Practice subscales, the Teaching Conditions scale, and the creating enriched environment subscale. Lowest ICCs were expected for subscales that were most closely related to a teacher's individual teaching style: the teacher sensitivity and teacher as a role model subscales.

Second, we calculated the correlations between the Teacher WEQ scores and the School Policy WEQ scores to evaluate the convergent and divergent validity of the scale scores. Because the teacher data was nested within schools, we used the between-school correlation as computed in the StatsBy function in the 'psych' R package (Revelle, 2021). We formulated four hypotheses based on the theoretical literature (see introduction): (1) the School Policy subscale 
scores are positively correlated to the Teaching Conditions and Teaching Strategies total scores; (2) these correlations are consistently higher for the School Practice scale compared to the School Mission scale; (3) these correlations are consistently higher for the Teaching Conditions total score than for the Teaching Strategies total score; and (4) correlations between subscale scores from teachers and principals addressing the same School Policy dimension (convergent validity) are higher than the correlations between scores from teachers and principals addressing different School Policy dimensions (divergent validity). To assess whether correlations differed significantly from zero, we used a two-sided $a=.05$. Because a combination of principal data and teacher data was only available for a subset of 47 schools, we had to restrict the correlations involving principal-rated scores to that subsample of data.

\section{Results}

\section{Teaching strategies (sub)scales}

\section{Item and scale statistics}

Item frequency distributions were generally skewed to the right; only four out of 33 items had $\geq 5 \%$ responses in the category 'not at all applicable'. Particularly the items in the subscales teacher sensitivity and teacher as a role model were skewed, with mean item scores ranging from 3.32 to 3.59. Corrected item-total correlations ranged from .29 to .56 within each Teaching Strategies subscale, suggesting that each of the items was sufficiently related to the remaining items in the same subscale. Cronbach's alpha equalled .91 for the total set of items and indicated a high reliability of the Teaching Strategies total score. For the separate subscales, Cronbach's alpha was low (.52) for the stimulating contemplation subscale (likely due to the low number of items in the subscale) but acceptable for the other subscales (range: 60 to .69). Correlations between subscale scores ranged from .22 (exploration and experimentation with teacher as a role model) to .64 (teacher as a role model and teacher sensitivity). The Appendix provides a detailed overview of the descriptive item and scale statistics (see Table A1).

\section{Dimensionality}

The ratio between the first and second eigenvalue was 3.92, indicating that there was a strong primary dimension in the data. Parallel analysis suggested two dimensions to underlie the data. The first two components explained $28.4 \%$ of the total variance. In the next step, we estimated an exploratory factor model with two factors. Table 2 shows the factor loadings for the two-factor model. Items with a factor loading $\geq .40$ on one factor and a cross loading $\leq .15$ on the other factor were used to interpret the factor (underlined in Table 2). Factor 1 was represented mainly by teacher as a role model (all items) and teacher sensitivity (4 out of 5 items). These items, as well as the other items with high loadings on this factor, suggested that Factor 1 could be interpreted as describing what teachers explicitly do themselves to guide and stimulate wonder in children. We therefore refer to this dimension as the 'Teacher' dimension. Factor 2 was mainly represented by exploration and experimentation (all items), meaning-making ( 2 out of 4 items), and creating enriched environment ( 3 out of 4 items). The items loading highly on this factor suggested that Factor 2 represents strategies that require a more active role of the children relative to that of the teacher. We therefore refer to this dimension as the 'Child' dimension.

Next, we estimated several confirmatory factor models; see Table 4 for the model-fit indices. As expected, the one-factor model showed poor fit. The theoretical eight-factor model showed good fit but 12 out of 28 factor correlations were very high $(r>.85)$, suggesting redundancy of most factors. Based on the two-factor EFA results, we also estimated a bi-factor model (Reise, 2012). This model included three uncorrelated factors: A 'General wonder-full education' factor that loaded on each of the items, a Teacher factor with loadings on the items that could be categorized into Factor 1, and a Child factor with loadings on the items that could be categorized into Factor 2 (see the underlined factor loadings in Table 2). This model showed good fit and standardized factor loadings were 
generally of acceptable size (ranging from .23 to .70). However, for three items (MM1, SI5, CEE1) loadings on the Child factor were small $(<.15)$, indicating that these items contributed little to the measurement of this specific factor.

Overall, the dimensionality results suggested that use of the eight subscale scores may be redundant. Considering the generally substantial positive correlations between the eight specific factors, the use of a total Teacher WEQ score seems justified as a general measure of wonder-full teaching strategies. Next to that, separate scores for items loading highly on a Teacher dimension and a Child dimension, respectively, seem important for making a distinction between predominantly teacher-led and child-led strategies.

\section{Teaching conditions scale}

Similar to the item scores for the Teaching Strategies scale, item frequency distributions for the Teaching Conditions scale were generally skewed to the right. Corrected item-total correlations for the full 33-item scale ranged from .43 to .67 and Cronbach's alpha equalled .94. Analysis of eigenvalues showed that the first component explained $44.4 \%$ of the total variance. The ratio between the first and second eigenvalue equalled 7.7. Because this ratio suggested the first factor to be so dominant, we did not further investigate the dimensionality of the Teaching Conditions scale and concluded that a single sum score represents the item set sufficiently well. Correlations between the Teaching Conditions score and the Teaching Strategies subscale scores ranged from .46 to .55. The Appendix provides a detailed overview of the descriptive item and scale statistics (see Table A1).

\section{School policy subscales}

\section{Item and scale statistics}

Most items in the School Practice scale (teacher report) and the School Mission scale (principal report) had a symmetric frequency distribution. Two items (TME1, CE3) had a response proportion below .05 for response option 'does not really apply' in both the principal and the teacher data. Corrected item-total correlations within subscales ranged from .26 to .72 across the teacher data and the principal data. Cronbach's alpha values were satisfactory to good in both the principal data and the teacher data, ranging from .73 (test and method centred education in the teacher data) to .82 (child exploration in both the teacher and principal data). Correlations between subscales were substantial, ranging from .46 to .65 . The Appendix provides a detailed overview of the descriptive item and scale statistics (see Table A2).

\section{Dimensionality}

The ratio between the first and second eigenvalue in both the teacher data and principal data was about 3.2. The first three components explained $65-69 \%$ of the total variance. Parallel analysis suggested three factors for the teacher data and two factors for the principal data. We therefore inspected exploratory factor models with two and three factors, respectively. In both datasets, the estimated two-factor model made a clear distinction between the positively worded items (Factor 1) and the negatively worded items (Factor 2). This is a common factor analytic outcome for psychological tests with a mixture of positively and negatively worded items (e.g. Baumgartner \& Steenkamp, 2001; Marsh, 1996). Table 3 shows the parameter estimates for the three-factor model. Results in both datasets provided support for the theoretical factor structure: Factor 1 represented child-focused education, Factor 2 represented test and method centred education, and Factor 3 represented enriched education. However, there were items in both the teacher data (CE2, TME1, TME4) and the principal data (EnE1, TME1, CE6, and TME4) that did not have the highest loading for 
the factor they were designed for. For CE2 and EnE1, the cross-loading could be well explained by their item content, but for CE6, TME1 and TME4 this was not the case.

Next, we conducted CFA. Table 4 (lower part) shows the model-fit indices for the estimated models. As expected from the EFA, the one-factor model fitted poorly in both the teacher and principal data. The three-factor model showed a mediocre model fit in the teacher data but good fit in the principal data. To assess whether some degree of model misfit in the three-factor model could be attributed to an effect of item wording, we included an orthogonal (i.e. uncorrelated with the other factors) 'method factor' for the negatively worded items in addition to the substantive factors (Marsh, 1996). Adding a method factor to the three-factor model increased model fit to good values in the teacher data and to excellent values in the principal data. In this extended model, the three substantive factors (child-focused education, test and method centred education, enriched education) were highly correlated $(r>.70)$ in both the teacher and principal data. Apart from a low loading for TME5 (.22) on the test- and method centred education factor in the teacher data, standardized factor loadings on the substantive factor were of acceptable size in both the teacher and principal data, ranging from .34 to .91. These values suggested that apart from TME5, all the other items were sufficiently related to the subscale factors after taking into account the method factor.

Overall, results suggested that the theoretical three-factor structure for the School Policy scale is acceptable and the use of separate subscale scores for the different dimensions is justified. Model misfit in the theoretical three-factor structure appeared to be mainly caused by a method effect due to item wording instead of an additional substantive nuisance factor.

\section{Validity coefficients}

\section{Intra-class correlation}

The intra-class coefficients computed for each of the teacher-rated (sub)scales generally confirmed our expectations (see the Methods section for an overview). The ICCs for the subscales child-focused education (.28), test and method centred education (.40), enriched education (.45), and the Teaching Conditions scale (.28) were relatively large. These high ICCs indicate that a relatively large proportion of the total variance in scores can be attributed to variability between schools. Also following expectations, near zero ICCs were found for teacher as a role model $(0.00)$ and teacher sensitivity (0.03), indicating that scores on these subscales are not school dependent. A noteworthy and unexpected result was that the ICC for stimulating the imagination also equalled zero. This result suggests that the extent to which teachers stimulate the imagination of children may be more related to personal teaching style than to school environment. ICC values for the remaining Teaching Strategies subscales ranged from .12 (meaning making) to .24 (encouraging contemplation).

Table 4. Model-fit Indices for Confirmatory Factor Models

\begin{tabular}{|c|c|c|c|c|c|}
\hline \multirow[b]{2}{*}{ Model } & \multirow[b]{2}{*}{$x^{2}$} & \multicolumn{4}{|c|}{ Model-fit indices } \\
\hline & & $d f$ & RMSEA & CFI & TLI \\
\hline & \multicolumn{5}{|c|}{ Teaching Strategies (teacher data, $N=220$ ) } \\
\hline One factor & $880.9^{* *}$ & 495 & 0.060 & 0.89 & 0.88 \\
\hline Eight factors & $668.0^{* *}$ & 467 & 0.044 & 0.94 & 0.93 \\
\hline \multirow[t]{2}{*}{ One general + two specific factors ${ }^{1}$} & $656.3^{* *}$ & 470 & 0.042 & 0.95 & 0.94 \\
\hline & \multicolumn{5}{|c|}{ School Practice (teacher data, $N=220$ ) } \\
\hline One factor & $462.4^{* *}$ & 119 & 0.117 & 0.87 & 0.85 \\
\hline Three factors & $290.7^{* *}$ & 116 & 0.084 & 0.93 & 0.92 \\
\hline \multirow[t]{2}{*}{ Three factors + method factor $^{1}$} & $141.7^{*}$ & 111 & 0.036 & 0.99 & 0.99 \\
\hline & \multicolumn{5}{|c|}{ School Mission (principal data, $N=91$ ) } \\
\hline One factor & $299.9^{* *}$ & 119 & 0.129 & 0.86 & 0.84 \\
\hline Three factors & $142.8^{*}$ & 114 & 0.053 & 0.98 & 0.97 \\
\hline Three factors + method factor ${ }^{1}$ & 119.0 & 111 & 0.028 & 0.99 & 0.99 \\
\hline
\end{tabular}

Note. ${ }^{*}=p<.001$ and ${ }^{*}=p<.05$;

${ }^{1}$ Models are based on results of the exploratory factor analyses. 
Table 5. Between-school Correlations for the Teacher-reported Scores and the Principal-reported Scores of School Policy Subscales.

\begin{tabular}{lccc}
\hline & CE-principal & TME-principal & EnE-principal \\
\hline Child-focused education (CE)-teacher & -.01 & .27 & .14 \\
Test and method centred education (TME)-teacher & .22 & .51 & .28 \\
Enriched education (EnE)-teacher & .01 & .26 & .30 \\
\hline
\end{tabular}

Note.The teacher report refers to the daily practice in school and the principal report refers to the school mission. Data from $n=$ 47 schools and $n=101$ teachers. Correlations in italic are significant given a two-sided $\mathrm{a}=0.05$

\section{Convergent and divergent validity}

Table 6 provides correlations between each of the Teacher WEQ (sub)scale scores (within-school averages) and the School Policy subscale scores. Our hypotheses concern the Teacher WEQ scale scores (i.e. the Teaching Conditions score and the Teaching Strategies total score) and therefore the results for the eight specific subscales are not discussed in detail. See the Methods sections for an overview of the hypotheses.

Hypothesis 1: The School Policy subscale scores were generally substantially and positively correlated with the two Teacher WEQ total scores (Table 6). These results are consistent with our expectation that teachers' teaching strategies and teaching conditions are positively affected by a school policy that is supportive for promoting wonder. However, the specific results regarding the principal-reported child-focused education subscale provided less support for convergent validity as its correlations with Teaching Strategies $(r=.13)$ and Teachings Conditions $(r=.03)$ were low and not statistically significant. Theoretically, these results are difficult to explain and therefore they may reflect a lack of validity of the child-focused education scale. Another low correlation was found for the principal rating of enriched education with the Teaching Strategies total score $(r=.14)$. However, this result is unlikely to point at a lack of validity since the principal rating of the enriched education subscale did correlate substantially $(r=.29)$ with the most relevant specific teaching strategy, creating enriched environment.

Hypothesis 2: The correlations between the Teacher WEQ scale scores and the teacher-reported School Practice subscale scores were consistently larger than the corresponding correlations between the Teacher WEQ scale scores and the principal-reported School Mission subscale scores (Table 6). These results are consistent with our expectation that teacher's teaching strategies and teaching conditions should be more strongly affected by the daily school practice than by the school

Table 6. Correlations for Teacher WEQ Scores and School Policy WEQ Scores

\begin{tabular}{lllllll}
\hline Teaching Strategies subscales & \multicolumn{3}{c}{} & \multicolumn{3}{c}{ School Policy subscales } \\
\cline { 2 - 7 } & \multicolumn{3}{c}{ Teacher rating } & & \multicolumn{2}{c}{ Principal rating } \\
\cline { 2 - 7 } & CE & TME & EnE & CE & TME & EnE \\
\cline { 2 - 7 } Teacher as a role model & $.26^{*}$ & $.21^{*}$ & .13 & .00 & -.01 & -.08 \\
\hline Teacher sensitivity & $.40^{*}$ & $.29^{*}$ & $.31^{*}$ & -.21 & -.03 & -.15 \\
Exploration and experimentation & $.53^{*}$ & $.43^{*}$ & $.55^{*}$ & .12 & $.31^{*}$ & .18 \\
Defamiliarizing the familiar & $.40^{*}$ & $.25^{*}$ & $.40^{*}$ & -.02 & .07 & .10 \\
Meaning making & $.47^{*}$ & $.33^{*}$ & $.42^{*}$ & .06 & $.27^{*}$ & $.26^{*}$ \\
Stimulating the imagination & $.42^{*}$ & $.26^{*}$ & $.36^{*}$ & -.07 & .19 & -.01 \\
Encouraging contemplation & $.32^{*}$ & $.18^{*}$ & $.39^{*}$ & .04 & .05 & .13 \\
Creating enriched environment & $.51^{*}$ & $.30^{*}$ & $.64^{*}$ & .13 & $.34^{*}$ & $.29^{*}$ \\
\hline Teaching Conditions & $.61^{*}$ & $.41^{*}$ & $.62^{*}$ & .13 & $.33^{*}$ & $.25^{*}$ \\
Teaching Strategies total & $.57^{*}$ & $.39^{*}$ & $.56^{*}$ & .03 & $.23^{*}$ & .14 \\
\hline
\end{tabular}

Note: $\mathrm{CE}=$ child-focused education; TME = test and method centered education; $\mathrm{EnE}=$ enriched education. ${ }^{*} p<.05$ given a twosided $\mathrm{a}=0.05$. 'Subsample of data from $n=47$ schools and $n=101$ teachers; between-school correlations are provided. 
mission. An alternative explanation is that correlations between the teacher-reported School Policy scales and the teacher-reported Teacher WEQ scale scores were relatively high because of response style effects. There is a large body of research showing that correlations between constructs assessed by the same informant tend to be higher compared to correlations between the same constructs assessed by different informants (Furr, 2017).

Hypothesis 3: Compared to the Teaching Strategies total score, the Teaching Conditions total score was more strongly correlated to each of the School Policy subscale scores (Table 6). Although some of the differences regarding the teacher-reported scores are small, these results are consistent with our expectation that teacher's teaching conditions are more strongly affected by school policy than teacher's actual teaching strategies.

Hypothesis 4: For the subscales test and method centred education and enriched education, correlations between ratings from teachers and principals addressing the same subscale (convergent validity) were higher than the correlations between scores from teachers and principals addressing different subscales (divergent validity), see Table 5. For the test and method centred education subscale, the pattern of correlations was particularly supportive of divergent and convergent validity. Moreover, the convergent correlation coefficient $(r=.51)$ was relatively high considering that principals were instructed to respond to the questions with regard to the school's mission and vision, and teachers with regard to the daily practice of the school. For the enriched education subscale, two of the divergent correlations ( $r=.26$ and $r=.28$ ) were almost as high as the convergent correlation coefficient $(r=.30)$ and results therefore indicated weaker support for validity. For the child-focused education subscale, the pattern of correlations clearly did not support our hypotheses regarding convergent and divergent validity: there was no relationship between the teacher report and principal report $(r=-.01)$ while some of the divergent correlation coefficients were substantial.

\section{Summary of validity results}

We generally confirmed our hypotheses regarding validity coefficients, providing support for the validity of most WEQ subscale scores. The exception concerned the child-focused education subscale, for which we found partial support only. For the teacher-reported data on this subscale we did find a positive ICC and positive correlations with the Teacher WEQ subscale scores. However, it was unexpected that the principal-reported scores on this scale did not correspond well to the teacherreported scores on both the School Policy WEQ and the Teacher WEQ. Lack of validity is one of the possible explanations for the absence of correspondence. An alternative, but not mutually exclusive, explanation is that the different instructions provided to principals and teachers resulted in meaningful differences on this particular School Policy subscale; that is, the daily practice of the school may diverge from the actual mission of the school. The child-focused education subscale includes items that are not very specific or tangible (e.g. stimulating creativity, curiosity, and a personal connection to the lesson content) but at the same time describe school characteristics that are universally desirable and therefore likely to be included in a 'theoretical' school mission.

\section{Discussion}

In the last decade the role of wonder in education has gained more attention, possibly to counterbalance the focus on efficiency, effectivity and students' standardized test results (e.g. D'Agnese, 2020; Egan et al., 2014; Geller et al., 2020; Di Paolantonio, 2019). In this study, we presented a theoretical framework that includes the specific dimensions of wonder-full education, as well as the Wonder-full Education Questionnaire (WEQ) as an operationalization of that framework. The eight 
different teaching strategies in the framework include being sensitive to children's wonder, showing children one's own wonder and fascination as a role model, stimulating them to explore and experiment, encouraging their meaning making with regard to the lesson contents, stimulating their imagination, drawing children's attention to the fascinating aspects of familiar objects or phenomena, facilitating contemplation, and creating an enriched environment. The three dimensions of school policy refer to a child-focused educational program that stimulates children's engagement with the lesson contents, teacher's opportunities to deviate from the predetermined lesson plans and curriculum to create space for children's interests, and an enriched school environment. Given the close link between the WEQ and our theoretical framework, our validation study provides not only information on the psychometric properties of the WEQ, but also informs theory development about the teaching strategies and school policy dimensions that facilitate wonder-full education.

From both a practical and theoretical viewpoint, one of the most important findings of the validation study concerns the dimensional structure of the 33 items of the Teaching Strategies scale. Based on the theoretical literature we made a distinction between eight strategies within the Teaching Strategies dimension. However, the dimensionality analyses showed that the use of various strategies by teachers - such as being a role model and being sensitive to children's wonder-were statistically so strongly related that an empirical distinction between most of the strategies seems to be redundant. More specifically, our results showed that the Teaching Strategies data could be described by two main dimensions: a Teacher dimension (referring to strategies that are predominantly teacher-led) and a Child dimension (referring to strategies that are predominantly child-led). Some of the eight theoretically identified teaching strategies could be placed within one of the two dimensions (e.g. teacher as a role model within the Teacher dimension and exploration and experimentation within the Child dimension). Other strategies were mixed in terms of these dimensionsboth empirically and theoretically. For example, stimulating the imagination may happen through storytelling (a teacher-led strategy; see item SI2) but also by letting children write a story (a child-led strategy; see item SI5).

Results regarding the reliability and validity of the Teacher WEQ are satisfactory. However, our results also suggest that future research might best work with a total WEQ Teaching Strategies score in combination with separate scores for items that fit either within the Teacher dimension or the Child dimension, respectively (see Table 2). Post-hoc analyses showed that such separate child and teacher scores were only moderately correlated $(r=.51)$, indicating that these dimensions may show interesting differential relationships with external variables.

For the School Policy WEQ, we largely confirmed the theoretical three-factor structure and we found that subscale scores had good reliability estimates. These results support the validity of the three subscale scores. The estimated validity coefficients generally provided additional validity evidence for the School Policy subscale scores. However, for the child-focused education subscale only partial support was found with respect to convergent validity. Results indicated that although teachers agree with each other regarding the degree to which their school stimulates child-focused education, teachers and principals are in little agreement about this. Furthermore, principal ratings of the degree to which a school offers child-focused education showed little correspondence with teaching strategies or teaching conditions as reported by teachers. One possible explanation is that school principals may have the mission to stimulate child-focused education, but they do so in different ways and therefore not necessarily through the wonder-promoting strategies as included in the Teacher WEQ. For example, a school may intend to stimulate children's personal connection with the lesson content through stimulating ownership of their learning (Chan et al., 2014) but such an educational practice would not stimulate wonder in children according to the wonder-full education framework. 


\section{Theoretical and practical implications}

This study has various implications for educational research and practice with regard to stimulating wonder at school. With regard to designing educational interventions, the wonder-full education framework provides a useful 'toolkit', complementing previous studies that have provided examples of how wonder may be stimulated during science lessons (e.g. Bianchi, 2014; Hadzigeorgiou, 2016). This toolkit of strategies is applicable to different types of lessons and children of various ages. Moreover, the wonder-full education framework suggests that wonder can be stimulated in various ways, ranging from being sensitive to children's wonder and providing time for reflection to taking children out into nature. This framework therefore suggests that stimulating wonder is possible across different school types and educational systems. On the other hand, our results suggest a substantial negative relationship between a test centred school policy and the use of teaching strategies for wonder: among the principal-rated school policy WEQ subscales, the test- and method centred education subscale showed the strongest relationships with Teacher WEQ (sub)scale scores. Therefore, it may be expected that national education systems with strong test-based accountability demands, such as the Netherlands or the UK, offer less opportunity for stimulating wonder as compared to countries such as Finland where standardized test scores are emphasized less and children are allowed more time and space for exploration (Sahlberg \& Doyle, 2019).

Furthermore, the WEQ provides the opportunity for research on wonder in education to be extended from mainly conceptual and theoretically driven work to empirical research. Studies using the WEQ may for example, compare the degree to which different school types or different national education systems are configured to foster wonder in children. The WEQ may also be used to investigate the hypothesized effect of stimulating and fostering wonder in children on socalled 21st-century skills such as creativity or innovative thinking (Gilbert \& Byers, 2017; Pedersen, 2019), and further to quantitatively replicate the positive effect of stimulating wonder on children's and teachers' emotional engagement (e.g. Gilbert \& Byers, 2017; Hadzigeorgiou, 2012). In such analyses, scale scores for specific types of strategies in the WEQ (e.g. the Teacher dimension score and Child dimension score) can also be used to investigate which specific strategies have the largest positive effects on child variables. Possible moderators of the relationship between the use of the wonder-full teaching strategies and child variables could herein also be taken into account. For example, several studies suggest that a good teacher-student relationship is a prerequisite for teachers to effectively stimulate children's wonder (e.g. Erlich, 2020; Griffiths, 2014; Riley, 2010).

Finally, future research should also include the wonder-full education questionnaire itself. This is particularly important given that the wonder-full education framework and the WEQ were thus far only tested in the Dutch context and no appropriate research design to realize a representative sample of schools. Particularly, the two-dimensional structure of the Teacher WEQ needs to be further supported via replication studies, given that we had limited sample size to statistically distinguish the eight different theoretical dimensions. So, future studies should investigate the psychometric properties of the WEQ in other samples and countries. Currently, together with colleagues in England, we are designing an English validation study, which will offer the opportunity to replicate the item and scale properties as well as the dimensional structure of the WEQ. Another limitation of our validation study is that we did not assess whether WEQ scores are actually related to the experiences of children at school. Ideally, future research should investigate whether higher WEQ scores correspond with more or stronger wonder experiences of children at school, for example, using the diary method of Hadzigeorgiou (2012) to assess children's wonder about the lesson content. Such research could potentially provide very strong support for the validity of the WEQ.

\section{Conclusion}

The newly developed theoretical framework and questionnaire for wonder-full education provide an useful overview of specific teaching strategies and school-policy dimensions relevant for 
promoting wonder in children. The dimensionality analyses of the Teacher WEQ can further inform theory development regarding teaching strategies for wonder: empirically, we identified two broad dimensions instead of eight separate strategies. The two dimensions made a distinction based on who takes a relatively active role in stimulating wonder, the teacher or the child. These results suggest that the use of some strategies is highly related, which could lead to a more concise measurement in future empirical research and an exploration of the underlying mechanisms of this two-dimensional structure in theoretical research. For the WEQ, the current reliability and validity results are satisfactory for the majority of (sub)scales. We conclude that both the framework and the validated questionnaire may be applied in diverse settings and allow ample opportunity for empirical research and practice into the effects of promoting wonder in education.

\section{Data availability statement:}

The data that support the findings of this study are available upon reasonable request from the corresponding author, JC. The data are not publicly available due to data containing information that could compromise the privacy/consent of research participants.

\section{Disclosure statement}

No potential conflict of interest was reported by the author(s).

\section{Funding}

This work was supported by the John Templeton Foundation [grant number 60815].

\section{Notes on contributors}

Dr. Judith M. Conijn is a post-doctoral researcher at the department of Educational and Family Studies, VU University Amsterdam. After obtaining her PhD in 2013 at Tilburg University, the Netherlands, she published mainly on psychometric topics regarding the development and validation of self-report questionnaires and the detection of aberrant item-response patterns. In the last few years, she has directed her main research focus to educational topics such as wonder in education.

Dr. Willeke Rietdijk is a post-doctoral researcher at the department of Educational and Family Studies, VU University Amsterdam. Following a decade of experience as an educational researcher in England, she obtained her PhD from the University of Southampton, UK, in 2019. Her research interests and expertise concern the intersection of science -, environmental, contemplative and holistic education, as well as consciousness studies. She also has expertise in first person research methods.

Dr. Evelien Broekhof is a post-doctoral researcher at the Department of Educational and Family Studies, VU University Amsterdam, The Netherlands. She obtained her PhD in developmental psychology in 2019 from Leiden University, the Netherlands. Her research focusses on the roles of affective states (e.g., guilt, empathy, and wonder) in the development of children's moral behaviours. She recently developed an instrument to quantitatively assess children's sense of wonder. In her research, she uses a variety of methods including experiments, questionnaires, observations and qualitative semi-structured interviews.

Dr. Lucija Andre is a post-doctoral researcher at the Research institute of Child Development and Education, University of Amsterdam. She completed her PhD in 2018 in Educational Sciences at the same university and subsequently worked as a postdoctoral researcher on the Wonder-full education project at the VU University Amsterdam. She has published on topics related to motivation for learning, work, health, and museum and music education, and particularly, on the role of positive attitudes such as future time perspective on students' and teachers' learning and career planning.

Dr. Anders Schinkel is an Associate Professor of Philosophy of Education at the department of Educational and Family Studies, VU University Amsterdam, The Netherlands. He has published on a range of topics in philosophy of education, as well as in philosophy of history, ethics, and other areas. In recent years he authored a number of articles on wonder and education, and his book Wonder and Education: On the Educational Importance of Contemplative Wonder appeared with Bloomsbury in November 2020. 


\section{ORCID}

Judith M. Conijn (iD) http://orcid.org/0000-0003-3788-9416

Willeke Rietdijk (iD http://orcid.org/0000-0003-1425-280X

Evelien Broekhof (iD http://orcid.org/0000-0003-2864-6447

Lucija Andre (iD http://orcid.org/0000-0002-2125-3264

Anders Schinkel (iD) http://orcid.org/0000-0003-3929-1418

\section{References}

Bandura, A., \& Walters, R. H. (1977). Social learning theory (Vol. 1). Prentice-hall.

Barbezat, D. P., \& Bush, M. (2014). Contemplative practices in higher education: Powerful methods to transform teaching and learning. Jossey-Bass.

Baumgartner, H., \& Steenkamp, J. B. E. M. (2001). Response styles in marketing research: A cross-national investigation. Journal of Marketing Research, 38(2), 143-156. https://doi.org/10.1509/jmkr.38.2.143.18840

Bianchi, L. (2014). The keys to wonder-rich science learning. In K. Egan, A. Cant, \& G. Judson (Eds.), Wonder-full education: The centrality of wonder in teaching, and learning across the curriculum (pp. 190-203). Routledge.

Blessinger, P., \& Carfora, J. M. (2015). Inquiry-based learning for multidisciplinary programs: A conceptual and practical resource for educators. Emerald Publishing Limited.

Broekhof, E., Conijn, J. M., Rietdijk, W., \& Schinkel, A. (2021). Waarover verwonderen kinderen zich, en hoe kun je verwondering stimuleren? [what do children wonder about, and how can you stimulate wonder?]. Zone, 1, 8-9. https://www.tijdschriftzone.nl/art/50-6321_Wat-is-verwondering

Browne, M. W., \& Cudeck, R. (1993). Alternative ways of assessing model fit. In K. A. Bollen \& J. S. Long (Eds.), Testing structural equation models (pp. 136-162). Sage.

Carson, R. (1998). The Sense of Wonder. HarperCollins.

Chan, P. E., Graham-Day, K. J., Ressa, V. A., Peters, M. T., \& Konrad, M. (2014). Beyond involvement: promoting student ownership of learning in classrooms. Intervention in School and Clinic, 50(2), 105-113. https://doi.org/10.1177/ 1053451214536039

Conijn, J. M., Schinkel, A., \& Rietdijk, W. (2020). Verwondering in het basisonderwijs [wonder in primary education]. DaltonVisie, 9(1), 14-17.

D'Agnese, V. (2020). Contrasting the neoliberal educational agenda: Wonder reconsidered. In A. Schinkel (Ed.), Wonder, education, and human flourishing: Theoretical, empirical, and practical perspectives (pp. 23-39). VU University Press.

D'Olimpio, L. (2020). Education and the arts: Inspiring wonder. In A. Schinkel (Ed.), wonder, education, and human flourishing: Theoretical, empirical, and practical perspectives (pp. 256-270). VU University Press.

Di Paolantonio, M. (2019). Wonder guarding against thoughtlessness in education. Studies in Philosophy and Education, 38(3), 213-228. https://doi.org/10.1007/s11217-018-9626-3

Egan, K. (1990). Romantic understanding: The development of rationality and imagination, ages 8-15. Routledge.

Egan, K. (1992). Imagination in teaching and learning ages 8-15. Routledge.

Egan, K. (2014). Wonder awe and teaching techniques. In K. Egan, A. Cant, \& G. Judson (Eds.), Wonder-full education: The centrality of wonder in teaching and learning across the curriculum (pp. 49-161). Routledge.

Egan, K., Cant, A., \& Judson, G. (2014). Wonder-full education: The centrality of wonder in teaching and learning across the curriculum. Routledge.

Erlich, D. (2020). On wonder: Wittgenstein, Buber, and educational practice. In A. Schinkel (Ed.), Wonder, education, and human flourishing: Theoretical, empirical, and practical perspectives (pp. 127-143). VU University Press.

Fleming, D. (2014). An educational leadership perspective: Managing and revealing the DNA of wonder in teaching and learning. In K. Egan, A. Cant, \& G. Judson (Eds.), Wonder-full education: The centrality of wonder in teaching and learning across the curriculum (pp. 178-189). Routledge.

Furr, R. M. (2017). Psychometrics: An introduction. SAGE Publications.

Geller, G., Caldwell, M., \& Merritt, M. W. (2018). The cultivation of wonder in the premedical learning environment: nurturing ethical character in the early formation of health professionals. Journal of College and Character, 19(3), 229-235. https://doi.org/10.1080/2194587X.2018.1481100

Geller, G., Steinman, C., Caldwell, M., Goldberg, H., Hanlon, C., Wonnell, T., \& Merritt, M. W. (2020). Development and validation of a capacity for wonder scale for use in educational settings. Journal of Psychoeducational Assessment, 38 (8), 982-994. https://doi.org/10.1177/0734282920918727

Gilbert, A., \& Byers, C. C. (2017). Wonder as a tool to engage preservice elementary teachers in science learning and teaching. Science Education, 101(6), 907-928. https://doi.org/10.1002/sce.21300

Glăveanu, V. P. (2017). Creativity and wonder. The Journal of Creative Behavior, 53(2), 171-177. https://doi.org/10.1002/ jocb. 225

Griffiths, M. (2014). Encouraging imagination and creativity in teaching profession. European Educational Research Journal, 13(1), 117-129. https://doi.org/10.2304/eerj.2014.13.1.117 
Gunnlaugson, O., Sarath, E. W., Scott, C., \& Bai, H. (Eds.). (2014). Contemplative learning and inquiry across disciplines. State University of New York Press.

Hadzigeorgiou, Y. (2014). Reclaiming the value of wonder in science education. In K. Egan, A. Cant, \& G. Judson (Eds.), Wonder-full education: The centrality of wonder in teaching and learning across the curriculum (pp. 40-65). Routledge.

Hadzigeorgiou, Y. (2016). Imaginative science education. The central role of imagination in science education. Springer International Publishing.

Hadzigeorgiou, Y. (2020). Wonder: Its nature and its role in the learning process. In A. Schinkel (Ed.), Wonder, education, and human flourishing: Theoretical, empirical, and practical perspectives (pp. 185-211). VU University Press.

Hadzigeorgiou, Y., \& Judson, G. (2017). Toward more effective storytelling for raising environmental awareness in young students. Journal of Advances in Education Research, 2(1), 12-18. https://doi.org/10.22606/jaer.2017.21002

Hadzigeorgiou, Y., Klassen, S., \& Klassen, C. F. (2012). Encouraging a 'romantic understanding' of science: the effect of the nikola tesla story. Science \& Education, 21(8), 1111-1138. https://doi.org/10.1007/s11191-011-9417-5

Hadzigeorgiou, Y., \& Schulz, R. M. (2019). Engaging students in science: the potential role of 'narrative thinking' and 'romantic understanding'. Frontiers in Education, 4(38). https://doi.org/10.3389/feduc.2019.00038

Hadzigeorgiou, Y. (2012). Fostering a sense of wonder in the science classroom. Research in Science Education, 42(5), 985-1005. https://doi.org/10.1007/s11165-011-9225-6

Hakkarainen, P. (2004). Narrative learning in the fifth dimension. Outlines. Critical Practice Studies, 6(1), 5-20. https:// tidsskrift.dk/outlines/article/view/2147

Hein, G. E. (1991). Constructivist learning theory. Institute for Inquiry. https://www.exploratorium.edu/education/ifi/ constructivist-learning

Hu, L., \& Bentler, P. (1999). Cutoff criteria for fit indices in covariance structure analysis. conventional criteria versus new alternatives. Structural Equation Modeling, 6(1), 1-55. https://doi.org/10.1080/10705519909540118

Jørgensen, K. (2016). Bringing the jellyfish home: environmental consciousness and 'sense of wonder' in young children's encounters with natural landscapes and places. Environmental Education Research, 22(8), 1139-1157. https://doi.org/10.1080/13504622.2015.1068277

Kashdan, T. B., \& Silvia, P. J. (2009). Curiosity and interest: The benefits of thriving on novelty and challenge. In S. J. Lopez \& C. R. Snyder (Eds.), The Oxford handbook of positive psychology (2nd ed, pp. 367-375). Oxford University Press.

L'Ecuyer, C. (2014). The wonder approach to learning. Frontiers in Human Neuroscience, 8, 764. https://doi.org/10.3389/ fnhum.2014.00764

Lindholm, M. (2018). Promoting Curiosity? Science \& Education, 27(9-10), 987-1002. https://doi.org/10.1007/s11191018-0015-7

Lindqvist, G. (1996). The aesthetics of play. A didactic study of play and culture in preschools. Early Years, 17(1), 6-11. https://doi.org/10.1080/0957514960170102

MacCallum, R. C., Browne, M. W., \& Sugawara, H. M. (1996). Power analysis and determination of sample size for covariance structure modeling. Psychological Methods, 1(2), 130-149. https://doi.org/10.1037/1082-989X.1.2.130

Marjanovic-Shane, A., Ferholt, B., Miyazaki, K., Nilsson, M., Rainio, A. P., Hakkarainen, P., Pešic, M., \& Belanski-Ristic, L. (2011). Playworlds: An art of development. In C. Lobman \& B. E. O'Neill (Eds.), Play and performance: Play and culture studies (volume 11) (pp. 3-32). University Press of America.

Marsh, H. W. (1996). Positive and negative global self-esteem: A substantively meaningful distinction or artifactors?. Journal of Personality and Social Psychology, 70(4), 810-819. https://doi.org/10.1037/0022-3514.70.4.810

Morgan, P. F. (2015). A brief history of the current reemergence of contemplative education. Journal of Transformative Education, 13(3), 197-218. https://doi.org/10.1177/1541344614564875

Muthén, L. K., \& Muthén, B. O. (1998-2017). Mplus user's guide (Eighth edition). Muthén \& Muthén.

Opdal, P. M. (2001). Curiosity, wonder and education seen as perspective development. Studies in Philosophy and Education, 20(4), 331-344. https://doi.org/10.1023/A:1011851211125

Pedaste, M., Mäeots, M., Siiman, L. A., Jong, T. D., Riesen, S. A., Kamp, E. T., \& Tsourlidaki, E. (2015). Phases of inquiry-based learning: definitions and the inquiry cycle. Educational Research Review, 14, 47-61. https://doi.org/10.1016/j.edurev. 2015.02.003

Pedersen, J. B. W. (2019). Balanced wonder: Experiential sources of imagination, virtue, and human flourishing. Lexington Books.

Piersol, L. (2014). Our hearts leap up: Awakening wonder within the classroom. In K. Egan, A. Cant, \& G. Judson (Eds.), Wonder-full education: The centrality of wonder in teaching and learning across the curriculum (pp. 3-21). Routledge.

Reise, S. P. (2012). The rediscovery of bifactor measurement models. Multivariate Behavioral Research, 47(5), 667-696. https://doi.org/10.1080/00273171.2012.715555

Revelle, W. (2021). Psych: procedures for psychological, psychometric, and personality research. Northwestern University, Evanston, Illinois. R package version 2.1.3, https://CRAN.R-project.org/package=psych

Riley, P. (2010). Attachment theory and the teacher-student relationship: A practical guide for teachers, teacher educators and school leaders. Routledge.

Sahlberg, P., \& Doyle, W. (2019). Let the children play: How more play will save our schools and help children thrive. Oxford University Press. 
Schinkel, A. (2017). On the educational importance of deep wonder. Journal of Philosophy of Education, 51(2), 538-553. https://doi.org/10.1111/1467-9752.12233

Schinkel, A. (2018). Wonder and moral education. Educational Theory, 68(1), 31-48. https://doi.org/10.1111/edth.12287

Schinkel, A. (2019). Education as mediation between child and world: The role of wonder. Studies in Philosophy and Education, 39(5), 1-14. https://doi.org/10.1007/s11217-019-09687-8

Schinkel, A. (2020). Concluding chapter: Implications for policy and practice. In A. Schinkel (Ed.), Wonder and education: On the educational importance of contemplative wonder (pp. 183-198). Bloomsbury.

Schinkel, A. (2021a). Wonder and education: On the educational importance of contemplative wonder (pp. 183-198). Bloomsbury.

Schinkel, A. (2021b). Wonderful education and human flourishing. The Wonderful Education Project. https://wonderful education.eu

Seidel, J. (2006). Some thoughts on teaching as contemplative practice. Teachers College Record, 108, 1901-1914. https:// www.tcrecord.org/Content.asp?Contentld $=12687$

Stolberg, T. L. (2008). W(h)ither the sense of wonder of pre-service primary teachers' when teaching science?: A preliminary study of their personal experiences. Teaching and Teacher Education, 24(8), 1958-1964. https://doi. org/10.1016/j.tate.2008.05.005

Trotman, D. (2014). Wow! What if? So what? Education and the imagination of wonder: Fascination possibilities and opportunities missed. In K. Egan, A. Cant, \& G. Judson (Eds.), Wonder-full education: The centrality of wonder in teaching and learning across the curriculum (pp. 22-39). Routledge.

Van Manen, M. (2016). Pedagogical tact: Knowing what to do when you don't know what to do (Vol. 1). Routledge.

Vasalou, S. (2015). Wonder: A grammar. State University of New York Press.

Vygotsky, L. S. (1978). The role of play in development. In L. S. Vygotstky \& M. Cole (Eds.), Mind in society (pp. 92-104). Harvard University Press.

Washington, H. (2018). Education for wonder. Education Sciences, 8(3), 125. https://doi.org/10.3390/educsci8030125

Wolbert, L., \& Schinkel, A. (2020). What should schools do to promote wonder?Oxford Review of Education, 1-16. https:// doi.org/10.1080/03054985.2020.1856648

Yun, S. (2018). Curiosity, wonder and museum education. Journal of Philosophy of Education, 52(3), 465-482. https://doi. org/10.1111/1467-9752.12303 


\section{Appendix}

Table A1. Descriptive statistics for Teacher WEQ items and correlations between subscale scores.

Correlations between (sub)scale scores

\begin{tabular}{|c|c|c|c|c|c|c|c|c|c|c|c|c|c|c|}
\hline Scale & Subscale & $\begin{array}{l}\text { Range of mean } \\
\text { item-score }\end{array}$ & $\begin{array}{c}\text { Range of } \\
r_{i t}\end{array}$ & $\begin{array}{c}\text { Cronbach's } \\
\text { Alpha }\end{array}$ & TRM & TS & $\mathrm{EE}$ & MM & DF & SI & CEE & $\mathrm{CO}$ & TC & $\mathrm{TS}_{\text {tot }}$ \\
\hline Teaching & TRM & $3.38-3.56$ & $.43-.51$ & .69 & 1 & & & & & & & & & \\
\hline \multirow[t]{7}{*}{ Strategies } & TS & $3.32-3.59$ & $.33-.48$ & .64 & .64 & 1 & & & & & & & & \\
\hline & $\mathrm{EE}$ & $2.67-3.25$ & $.33-.59$ & 69 & .22 & .47 & 1 & & & & & & & \\
\hline & DF & $2.81-3.21$ & $.34-.48$ & .62 & .37 & .50 & .58 & 1 & & & & & & \\
\hline & MM & $3.01-3.39$ & $.33-.47$ & .60 & .53 & .57 & .46 & .49 & 1 & & & & & \\
\hline & SI & $2.94-3.28$ & $.30-.42$ & .61 & .58 & .60 & .47 & .56 & .61 & 1 & & & & \\
\hline & CEE & $2.10-3.22$ & $.29-.56$ & .68 & .29 & .43 & .48 & .51 & .45 & .49 & 1 & & & \\
\hline & $\mathrm{CO}$ & $2.79-3.39$ & $.32-.55$ & .52 & .50 & .53 & .40 & .50 & .58 & .60 & .49 & 1 & & \\
\hline \multicolumn{2}{|c|}{ Teaching Conditions } & $2.32-3.52$ & $.46-.69$ & .94 & .50 & .55 & .46 & .50 & .46 & .55 & .53 & .51 & 1 & \\
\hline \multicolumn{2}{|c|}{$\begin{array}{l}\text { Teaching Strategies } \\
\text { (total) }\end{array}$} & - & - & .91 & .66 & .76 & .66 & .76 & .79 & .80 & .71 & .76 & .69 & 1 \\
\hline
\end{tabular}

Note. TRM = Teacher as a role model; TS = Teacher sensitivity; EE = Exploration and experimentation; DF = Defamiliarizing the familiar; $\mathrm{MM}=$ Meaning making; $\mathrm{SI}=$ Stimulating the imagination; $\mathrm{CEE}=$ Creating enriched environment; $\mathrm{CO}=$ Encouraging Contemplation; $\mathrm{TC}=$ Teaching conditions; $\mathrm{TS}_{\text {tot }}=$ Teaching Strategies total score. $\mathrm{r}_{\mathrm{it}}$ is the corrected item-total correlation within a subscale.

Table A2. Descriptive statistics for School Policy WEQ items and correlations between School Policy WEQ subscale scores.

\begin{tabular}{|c|c|c|c|c|c|c|c|c|c|}
\hline & \multicolumn{2}{|c|}{$\begin{array}{l}\text { Range of mean } \\
\text { item-score }\end{array}$} & \multicolumn{2}{|c|}{ Range of $r_{i t}$} & \multicolumn{2}{|c|}{ Cronbach's Alpha } & \multicolumn{3}{|c|}{ Correlations between subscale scores } \\
\hline & Teachers & Principals & Teachers & Principals & Teachers & Principals & $\mathrm{CE}$ & TME & EnE \\
\hline CE & $1.9-2.5$ & $2.1-2.5$ & $.50-.67$ & $.42-.69$ & .82 & .82 & 1.00 & .53 & .64 \\
\hline TME & $1.5-2.5$ & $1.5-2.7$ & $.33-.58$ & $.33-.69$ & .73 & .78 & .46 & 1.00 & .55 \\
\hline EnE & $1.8-2.3$ & $1.8-2.5$ & $.26-.58$ & $.37-.72$ & .81 & .79 & .65 & .47 & 1.00 \\
\hline
\end{tabular}

Note. $r_{\text {it }}$ is the corrected item-total correlation within a subscale. $C E=$ child-centred education; TME $=$ test and method centred; $\mathrm{EnE}=$ enriched education. $n=220$ for the teacher-reported data and $n=91$ for the principal-reported data. ${ }^{1}$ Correlations are provided for both the teacher data (below the diagonal) and for the principal data (above the diagonal). 